\title{
POSSIBILIDADES DE CARREIRA COMO FATOR DE QUALIDADE DE VIDA NO TRABALHO
}

\author{
ARTIGO ORIGINAL \\ COLOMBO, Flávia Vanessa Bandeira ${ }^{1}$ \\ FURLANETTO, Stéfani Destefano ${ }^{2}$ \\ ALVES, Priscila Viviane ${ }^{3}$ \\ SCATOLIN, Henrique Guilherme ${ }^{4}$
}

COLOMBO, Flávia Vanessa Bandeira. Et al. Possibilidades de carreira como fator de qualidade de vida no trabalho. Revista Científica Multidisciplinar Núcleo do Conhecimento. Ano 05, Ed. 03, Vol. 10, pp. 155-167. Março de 2020. ISSN: 24480959, Link de acesso: https://www.nucleodoconhecimento.com.br/psicologia/possibilidades-decarreira

\section{RESUMO}

O atual cenário competitivo e complexo no qual as organizações encontram-se inseridas vem exigindo das mesmas condutas capazes de gerar diferenciais competitivos. Neste contexto, o termo qualidade de vida no trabalho vem sendo largamente utilizado como uma importante ferramenta de gestão dentro das

1 Pós-graduação em Psicologia Organizacional e do Trabalho. Graduação em Psicologia.

2 Pós-graduação em Psicologia Organizacional e do Trabalho. Graduação em Administração de Empresas. Graduação em Tecnologia de Recursos Humanos.

3 Pós-graduação em Psicologia Organizacional e do Trabalho, Graduação em Tecnologia de Recursos Humanos.

${ }^{4}$ Doutor em Psicologia. 
organizações, objetivando aos trabalhadores maior bem estar, satisfação no trabalho e menos desgaste emocional. $O$ artigo pautou-se no modelo de análise sobre Qualidade de Vida no Trabalho da obra de Walton (1973) que consiste em oito categorias, destacando-se a quarta categoria que se trata da "Oportunidade futura para crescimento contínuo e segurança". Diante dessa categoria, trabalharemos com a seguinte problemática: como $\circ \mathrm{RH}$ pode promover possibilidades de carreira objetivando a qualidade de vida no trabalho? Frente à problemática apresentada, essa pesquisa se dá à partir de uma revisão de literatura tendo por objetivo suscitar reflexões a respeito das ferramentas que auxiliam a gestão de $\mathrm{RH}$ a promover possibilidades de carreira ao trabalhador propiciando qualidade de vida no trabalho. Considerou-se à partir das referências bibliográficas pesquisadas, que a gestão de recursos humanos pode promover desenvolvimento de carreira objetivando a qualidade de vida no trabalho através de práticas que contemplem o gerenciamento de carreiras, com previsões das necessidades da gestão de pessoas e da elaboração de projetos voltados para fins de recrutamento interno, avaliação de desempenho visando a evolução profissional, dentre outras práticas. As principais considerações deste artigo convergem para a importância desta competência em QVT resultando em novos conhecimentos e ações, condutas empresariais, conquistas, desenvolvimento de habilidades dos empregados e da distribuição de responsabilidades entre organização e empregados.

Palavras-chave: Qualidade de vida, trabalho, satisfação, carreira.

\section{INTRODUÇÃO}

O atual cenário competitivo e complexo no qual as organizações encontram-se inseridas vem exigindo das mesmas condutas capazes de gerar diferenciais competitivos. Neste contexto, o termo qualidade de vida no trabalho vem sendo largamente utilizado como uma importante ferramenta de gestão.

Neste sentido, o tema qualidade de vida no trabalho (QVT), através de suas implementações, tem sido compreendido como um diferencial para manter o trabalhador motivado e comprometido, gerando benefícios como satisfação e 
sentimento de bem-estar para o mesmo e, de outro lado, resultados almejados pelas empresas como aumento da produtividade, qualidade em seus produtos finais, dentre outros.

Limongi França (2009) conceitua qualidade de vida no trabalho como sendo a habilidade de gerenciar um agrupamento de ações, englobando diagnóstico, melhorias, aperfeiçoamentos gerenciais, tecnológicos e estruturais no campo laboral, tendo como base a cultura organizacional, visando sobretudo o bem-estar dos trabalhadores da organização. Sendo assim, atualmente a qualidade de vida no trabalho configura a necessidade de ressaltar as condições de trabalho abrangendo desde o cuidado com a ergonomia até os bons padrões de interação.

A qualidade de vida no trabalho é um conceito que objetiva melhorar a QV dos empregados dentro das organizações, de modo que eles tenham maior bem estar, satisfação no trabalho e também menos desgaste emocional. Trata-se de uma forma pela qual os integrantes da organização, através das vias de comunicação disponíveis e adequadas, caminham para tal finalidade, tendo voz ativa nas deliberações que afetam sua função e, em especial, o ambiente laboral como um todo, conforme leitura de Ogata e Simurro (2018) da obra de Dolan (2006). Neste sentido, qualidade de vida no trabalho envolve também condições adequadas onde o profissional se sinta respeitado, sendo que estas condições são consideradas um dos principais fatores que afetam as atitudes pessoais e comportamentais do profissional, influenciando a realização do indivíduo no trabalho.

À partir do entendimento de que o funcionário representa um participante fundamental na produtividade da empresa, Gonçalves et al. (2005) compreende que é inequívoco que ela se preocupe com a manutenção e promoção da saúde do mesmo, do ponto de vista físico, emocional e espiritual. Neste sentido, muitos programas de qualidade de vida na empresa são desenvolvidos objetivando prevenir doenças e proporcionar ambiente agradável ao funcionário para a realização das tarefas laborais.

Uma política de qualidade de vida na empresa, de acordo com Gonçalves et al. (2005), visa promover condições adequadas no local de trabalho à partir da concepção ampla 
da vida do ser humano. Isso significa que são diversas as articulações possíveis neste campo. Daí a necessidade de conhecer as características da cultura organizacional e as práticas tradicionais de $\mathrm{RH}$ já existentes na empresa (como a Medicina e a Segurança do Trabalho), práticas de integração de novos colaboradores, dentre outras, que atendem aos objetivos da gestão da qualidade de vida e que devem ser articuladas com as novas propostas.

Na leitura de Limongi-França (2004) da obra de Walton (1973), a autora expõe um importante modelo de análise sobre Qualidade de Vida no Trabalho com oito categorias relacionadas à compensação justa, condições adequadas de trabalho, oportunidades de desenvolvimento, oportunidades para crescimento contínuo, integração social, constitucionalismo, trabalho e espaço total na vida do indivíduo e relevância social do trabalho.

Com base na leitura de Rodrigues (1994) da obra de Walton (1973), dentre as oito categorias de qualidade de vida, destacamos a $4^{\text {a }}$ "Oportunidade futura para crescimento contínuo e segurança", que envolve os seguintes aspectos: aplicação respectiva: aplicar o conhecimento e as habilidades já existentes e recém-adquiridas no desenvolvimento das atribuições do trabalhador;

Desenvolvimento: fazer uso das atribuições do trabalhador como forma de expandir sua capacidade, evitando o retrocesso do próprio e da organização;

Oportunidade de progresso: observam-se as oportunidades da organização progredir e as oportunidades de crescimento profissional oferecidas pela organização;

Segurança: através do bom desenvolvimento das atribuições o trabalhador sente segurança de emprego.

Diante da definição da 4⿳亠丷a categoria, trabalharemos com a seguinte problemática: como o $\mathrm{RH}$ pode promover possibilidades de carreira objetivando a qualidade de vida no trabalho? 
Frente à problemática apresentada, essa pesquisa se dá à partir de uma revisão de literatura tendo por objetivo suscitar reflexões a respeito das ferramentas que auxiliam a gestão de $\mathrm{RH}$ a promover possibilidades de carreira ao trabalhador propiciando qualidade de vida no trabalho.

\section{METODOLOGIA}

Tendo em vista o objetivo deste artigo que é abordar o tema qualidade de vida no trabalho sob a perspectiva da $4^{\mathrm{a}}$ categoria da teoria de Walton (1973), o método de pesquisa utilizado consistiu em uma revisão de literatura, sendo que os descritores foram: qualidade de vida, trabalho, satisfação e carreira.

As pesquisas foram baseadas em vinte livros e onze artigos, sendo que do total do material pesquisado foram selecionados onze livros, três revistas, uma dissertação de mestrado e um artigo. Os critérios de inclusão destes materiais estão relacionados ao objetivo desta pesquisa, materiais recentes e títulos relacionados aos quatro descritores mencionados acima. Os critérios para a eliminação de artigos foram aqueles com data de publicação anterior ao ano de 2006 com exceção de alguns livros e revistas cujos autores são considerados pioneiros na questão estudada. O critério para a eliminação de livros foram temas e conteúdos que não abrangem a problemática deste trabalho, porque é necessário realizar um estudo do material que será utilizado na pesquisa e selecionar à partir dos dados encontrados, as informações que serão apropriadas para o estudo.

Azevedo (1999) afirma que a revisão de literatura visa, através de uma seleção analítica de várias obras, apresentar o período atual da pesquisa sobre determinado objeto. A revisão bibliográfica não se trata de um texto original, mas um trabalho que permite ao autor comparar e avançar sobre o seu tema, possibilitando realizar críticas sobre a abordagem das informações dadas pelos autores ao assunto pesquisado.

Traldi e Dias (2011) na leitura da obra de Bastos et al.(1982) afirmam que o objetivo da revisão de literatura é realizar uma amostragem investigativa sobre o tema, listando os principais trabalhos científicos contidos no campo e também uma união entre a 
bibliografia pesquisada e a situação-problema do estudo. O foco desse capítulo ou subseção é estabelecer um melhor entendimento do leitor com as produções existentes, autores, data e local. Tem como objetivo também prover com base no esboço de várias posições teóricas, um molde conceitual que sirva de base para a derivação da hipótese e especificação de sua fundamentação.

Neste sentido, a revisão de literatura procura realizar uma abordagem do tema apresentando os trabalhos mais importantes na área e realizando uma junção entre a bibliografia pesquisada e a situação problema em questão.

Como nos ensina Bento (2012):

A revisão da literatura é uma parte vital do processo de investigação. Aquela envolve localizar, analisar, sintetizar e interpretar a investigação prévia (revistas cientificas, livros, atas de congressos, resumos, etc.) relacionada com a sua área de estudo; é, então, uma análise bibliográfica pormenorizada, referente aos trabalhos já publicados sobre o tema. (BENTO, 2012, p. 01)

Sendo assim, a revisão em questão é uma parte essencial no exercício investigativo, abrangendo diversas etapas relativas ao campo estudado.

Desta maneira, o presente artigo acaba por permitir diferentes leituras do tema abordado, sendo a revisão de literatura pertinente para esse fim.

\section{FUNDAMENTAÇÃO TEÓRICA}

O conceito de qualidade de vida no trabalho, tema de competência da área de Gestão de Pessoas, apresenta uma imprecisão em sua definição apesar de ser amplamente discutido em todo o mundo. Pode-se atribuir parte desta dificuldade à abrangência do tema, bem como a sua carga de subjetividade, visto englobar noções como a de satisfação, motivação, bem-estar, saúde e segurança no trabalho, dentre outras. Além disso, a definição da qualidade de vida sofreu diversas alterações no decorrer do 
tempo, conforme afirma Guedes (2009). Contudo, observa-se que estas alterações não representam que atualmente exista uma definição clara e objetiva.

Do ponto de vista conceitual, Limongi-França (1997) entende que qualidade de vida no trabalho engloba diversas ações em uma empresa que abrange desde a implantação de melhorias contínuas, aperfeiçoamento gerencial, tecnológico, ambiental, dentre outras. Neste sentido, a implementação da qualidade de vida no trabalho se dá no momento que se concebe a empresa e as pessoas como um todo, enfoque este chamado de biopsicossocial. Nestes termos, o posicionamento biopsicossocial possibilita a realização de diagnóstico, geração de serviços e proposição de projetos com a finalidade de desenvolver as pessoas durante o trabalho na empresa.

A autora ainda explica que "a origem do conceito vem da medicina psicossomática que propõe uma visão integrada, holística do ser humano, em oposição à abordagem cartesiana que divide o ser humano em partes." (LIMONGI-FRANÇA, 1997, p. 80). Conclui afirmando:

no campo do trabalho esta abordagem pode ser associada à ética da condição humana. Esta ética busca desde a identificação, eliminação, neutralização ou controle de riscos ocupacionais observáveis no ambiente físico, padrões de relações de trabalho, carga física e mental requerida para cada atividade, implicações políticas e ideológicas, dinâmica da liderança empresarial e do poder formal até o significado do trabalho em si, relacionamento e satisfação no trabalho. (LIMONGIFRANÇA, 1997, p. 80)

A autora considera que a sociedade atual vivência novas formas de vida dentro e fora das organizações, engendrando, deste modo, novas demandas de qualidade de vida em todos os contextos. Acrescenta-se a esta realidade o aumento da expectativa de vida, o prolongamento da carreira profissional, a consciência do direito à saúde, dentre tantos outros aspectos desta nova realidade. 
Nesta conjuntura, a qualidade de vida no trabalho tem sido vista como um indicador das experiências humanas no contexto do trabalho e do grau de satisfação dos funcionários. Paralelo a esta questão, para que as organizações alcancem suas metas de produtividade, as mesmas precisam de colaboradores motivados e que participem da organização, sendo assim, a gestão da qualidade de vida configura-se em um modo de envolver o colaborador, possibilitando maior bem-estar e, consequentemente potencializando a eficácia organizacional (Chiavenato, 2004).

Neste sentido, observa-se certo consenso entre os autores no que diz respeito à abrangência do conceito qualidade de vida no trabalho.

Conforme quadro abaixo, Nadler e Lawler (1983) citado por Fernandes (1996) expõe o seu entendimento sobre as concepções evolutivas da qualidade de vida no trabalho.

Quadro 1 - Concepções Evolutivas da QVT

\begin{tabular}{|c|c|}
\hline $\begin{array}{l}\text { CONCEPÇÕES EVOLUTIVAS DO } \\
\text { QVT }\end{array}$ & CARACTERÍSTICAS OU VISÃO \\
\hline $\begin{array}{l}1 \text { - QVT como uma variável (1959 a } \\
\text { 1972) }\end{array}$ & $\begin{array}{l}\text { Reação do indivíduo ao trabalho. Era } \\
\text { investigado como melhorar a qualidade de } \\
\text { vida no trabalho para o indivíduo. }\end{array}$ \\
\hline $\begin{array}{l}2 \text { - QVT como uma abordagem } \\
\text { (1969 a 1974) }\end{array}$ & $\begin{array}{l}\text { O foco era o indivíduo antes do resultado } \\
\text { organizacional; mas, ao mesmo tempo, } \\
\text { tendia a trazer melhorias tanto ao } \\
\text { empregado como à direção. }\end{array}$ \\
\hline $\begin{array}{l}3 \text { - QVT como um método (1972 a } \\
\text { 1975) }\end{array}$ & $\begin{array}{l}\text { Um conjunto de abordagens, métodos ou } \\
\text { técnicas para melhorar o ambiente de } \\
\text { trabalho e tornar o trabalho mais produtivo e } \\
\text { mais satisfatório. QVT era visto como } \\
\text { sinônimo de grupos autônomos de trabalho, } \\
\text { enriquecimento de cargo ou desenho de } \\
\text { novas plantas com integração social e } \\
\text { técnica. }\end{array}$ \\
\hline
\end{tabular}




\section{4 - QVT como um movimento (1975 Declaração ideológica sobre a natureza do a 1980) trabalho e as relações dos trabalhadores com a organização. Os termos - administração participativa e democracia industrial - eram frequentemente ditos como ideais do movimento de QVT. \\ 5 - QVT como tudo (1979 a 1982) Como panacéia contra a competição estrangeira, problemas de qualidade, baixas taxas de produtividade, problemas de queixas e outros problemas organizacionais. \\ 6 - QVT como nada (futuro) $\quad$ No caso de alguns projetos de QVT fracassarem no futuro, não passará de apenas um "modismo" passageiro.}

Fonte: Fernandes,1996.

O Quadro sobre a Evolução do Conceito de QVT acima apresenta os períodos e os aspectos sobre a Qualidade de Vida no Trabalho. O objetivo desta exposição consiste em demonstrar que o conceito em questão vem passando por transformações ao longo dos anos e que estas mudanças estão relacionadas com a evolução dos paradigmas da sociedade como um todo. Vale ressaltar também que não foi localizada na literatura pesquisada, referências referentes a possíveis épocas futuras na qual a concepção do termo QVT como nada fosse referenciada.

Ao elaborar as políticas da organização é importante que se considere as necessidades humanas básicas. Na leitura de Hersey e Blanchard (1986) da obra de Maslow (1927), os autores comentam o interessante esquema para apresentar a intensidade de certas necessidades, uma vez que o comportamento das pessoas em alguns momentos podem ser determinados pelas suas necessidades mais acentuadas. 
Ao explicar essas necessidades, Maslow (1927) utilizou uma pirâmide onde cada necessidade está em um nível. Ao atingir a satisfação de cada necessidade, outros níveis tornam-se importantes e passam a motivar e dominar o comportamento das pessoas.

Segundo os autores, a base da pirâmide retrata as necessidades fisiológicas que são consideradas as necessidades básicas para a subsistência (alimento, roupa e moradia), sendo que as mais complexas estão voltadas para alcançar a satisfação pessoal e profissional. Ao atingir o nível de satisfação das necessidades fisiológicas, a próxima necessidade será a de Segurança, nessa necessidade podemos observar a autopreservação, que é a preocupação com o futuro (emprego, alimento e moradia), ao sentirem que essa necessidade está em ameaça as pessoas não veem importância em outras tarefas. Ao atingir a satisfação das necessidades fisiológicas e de segurança, ainda segundo os autores predominará a necessidade Social ou de Participação. Nela as pessoas sentem a necessidade de pertencerem e serem aceitas por vários grupos, consequentemente virá a necessidade de Estima, complementando a aceitação por vários grupos e a autoestima (reconhecimento e respeito por parte dos outros). A satisfação da necessidade de estima faz com que as pessoas produzam sentimentos de confiança em si mesmo, prestígio, poder e controle. Em algumas pessoas podem ocorrer de não atingirem a satisfação da necessidade de estima através de um comportamento construtivo, onde poderão apresentar comportamento destrutivo ou imaturo para satisfazer o desejo de atenção. Se essa necessidade for dominante, podemos considerar, como exemplo, a rebeldia e empregados que negligenciam o trabalho ou discutem com os companheiros e superiores.

De acordo com os autores citados anteriormente, tais comportamentos fazem com que essas pessoas não consigam o reconhecimento por meio do comportamento maduro ou de adaptação e sim através de comportamentos perturbadores e irresponsáveis. Porém, quando as pessoas atingem adequadamente a necessidade de estima, a necessidade de Auto Realização começa a predominar. Nela as pessoas sentem a necessidade de maximizar o seu próprio potencial, independente de qual for. A auto realização é o desejo de tornar-se aquilo de que se é capaz. 
Importante destacar que, na visão dos autores da obra de Maslow (1927), a maneira como a auto realização se expressa poderá mudar no decorrer da vida das pessoas, conforme seus objetivos. Outro aspecto a ser considerado é que na hierarquia das necessidades de Maslow podem ocorrer inúmeras exceções, onde as pessoas poderão seguir para uma determinada necessidade mesmo não estando totalmente satisfeitas com suas outras necessidades e que, ao predominar a necessidade de uma nova categoria sobre a outra, não quer dizer que esta esteja totalmente satisfeita e sim pode estar satisfeita de alguma forma.

Nesta conjuntura, Ferreira et al. (2006) na leitura da obra de Alderfer (1973), aponta que este autor realizou uma revisão da teoria de Maslow (1927) deixando-a mais moderna e dinâmica, pois, considera que mais de uma necessidade pode estar ativa ao mesmo tempo, sem seguir a uma estrutura rígida. Como exemplo cita que uma pessoa apesar de estar com a necessidade fisiológica insatisfeita, poderá estar trabalhando em seu crescimento pessoal.

Neste contexto das necessidades humanas básicas dentro das organizações, observa-se que as ações em qualidade de vida no trabalho objetivam o atendimento da camada biológica, ou seja, ações que focalizam atividades voltadas para a alimentação, saúde e ao tratamento de vícios apresentados pelos colaboradores, dentre outros. Observa-se uma escassez nas ações que compreendam a camada social, como por exemplo, o desenvolvimento de atividades envolvendo reciclagem, ações em cidadania, dentre outras. Também em menor quantidade as atividades com vistas ao atendimento da camada psicológica, como exemplo, pode-se citar o desenvolvimento de ações que envolvam lazer externo, tratamentos terapêuticos, dentre outras (Limongi-França, 2010, p. 174).

Em decorrência da dificuldade em definir o conceito de qualidade de vida no trabalho surgiram ao longo dos anos vários modelos que buscaram explicar o constructo. Porém, devido à quase impossibilidade de trazer neste artigo todos os modelos existentes na literatura, será apresentado o modelo de Walton (1973). 
Para Guedes (2009), o modelo referido "é o único que considera os elementos mais micro organizacionais, tais como condições físicas e aspectos relacionados com a segurança e com a remuneração" (GUEDES, 2009, p. 4). Em sua obra, o autor propõe um modelo multidimensional no qual considera que a qualidade de vida no trabalho é composta por oito dimensões. Considerando que todas estas foram apresentadas na introdução deste trabalho, discorreremos sobre a quarta dimensão por estar intrinsecamente ligada à problemática deste artigo, qual seja: como $\circ \mathrm{RH}$ pode promover possibilidades de carreira objetivando a qualidade de vida no trabalho?

Esta dimensão da obra de Walton (1973) citada pela Limongi-França (2004), Rodrigues (1994) e Guedes (2009) englobam as políticas da organização no que se referem às condições de desenvolvimento, progresso de seus colaboradores, dentre outras. Estas ações promovem possibilidades de carreira, crescimento pessoal e qualidade de vida.

A carreira representa um importante indicador das oportunidades de desenvolvimento profissional que uma empresa possibilita aos seus profissionais. Observa-se que não existe um consenso neste campo, pois, de um lado estão as empresas com sistemas bem estruturados para gerenciar a trajetória de seus profissionais às estratégias da organização e, do outro, estão aquelas empresas onde sobressaem as escolhas subjetivas de pessoas para o progresso. Esse panorama representa 0 atual contexto de trabalho e a gestão da organização nesta temática (Tolfo, 2002).

Para Limongi-França (2009) a recomendação atual é de que a gestão da carreira seja compartilhada tanto pela pessoa quanto pela organização. Nestes termos, a pessoa deve planejar sua carreira visando manter-se competitiva profissionalmente ao longo do tempo. Por outro lado, as organizações devem estimular este desenvolvimento de carreira da pessoa dentro dela, com vistas à valorização do capital humano a resultar no desenvolvimento da própria organização.

Nesta conjuntura, as práticas de gerenciamento de carreira pelas empresas abrangem uma previsão das necessidades da Gestão de Pessoas, projeto de desenvolvimento, 
de recrutamento interno, práticas bem estruturadas de avaliação de desempenho e da evolução profissional e etc. (Limongi-França, 2009).

A partir da fundamentação teórica apresentada, discutiremos abaixo como as organizações podem desenvolver ações que visam a valorização de seus colaboradores e também o bem estar dos mesmos à partir da problemática proposta neste estudo.

\section{RESULTADOS E DISCUSSÃO}

Considerando os conceitos trabalhados, bem como a problemática deste artigo, observa-se uma imprecisão na definição do termo qualidade de vida no trabalho, podendo abranger noções de satisfação, motivação, bem-estar, saúde e segurança no trabalho.

$\mathrm{Na}$ concepção da Limongi-França (1997) a sociedade moderna convive com novas demandas de se viver, influenciando novas necessidades de qualidade de vida em todos os contextos. Esta afirmação encontra correspondência na concepção do Chiavenato (2004) de que a qualidade de vida no trabalho tem sido compreendida como um indicador das experiências humanas no contexto do trabalho e do grau de satisfação dos funcionários.

Observou-se nas pesquisas realizadas que a elaboração das políticas da organização, no que tange a qualidade de vida no trabalho, estão predominantemente ancoradas na camada biológica. Sendo assim, relega-se para segundo plano a camada social e a camada psíquica.

A quarta dimensão da obra de Walton (1973), que versa sobre as oportunidades futuras para o crescimento contínuo e segurança, serviram de base para as reflexões deste artigo especificamente no que diz respeito à percepção de que as políticas da organização devem estar em sintonia com as condições de desenvolvimento e progresso de seus colaboradores. Outro ponto importante é considerar que estas 
condições de desenvolvimento podem promover oportunidades de carreira gerando sentimento de segurança no emprego.

Considerou-se, à partir das referências bibliográficas pesquisadas, que a gestão de recursos humanos pode promover desenvolvimento de carreira objetivando a qualidade de vida no trabalho através de práticas, conforme exemplifica a LimongiFrança (2009), que contemplem o gerenciamento de carreiras, com previsões das necessidades da gestão de pessoas e da elaboração de projetos voltados para fins de recrutamento interno, avaliação de desempenho visando a evolução profissional, dentre outras práticas.

\section{CONCLUSÃO}

Seguramente a qualidade de vida no trabalho faz parte das mudanças pelas quais passam as relações e as condições de trabalho na sociedade moderna.

Os atuais paradigmas de gestão de pessoas no século XXI decerto apontam para uma atuação gerencial socialmente mais responsável e mais engajada com as condições de trabalho de seu principal ativo, que são seus funcionários, construída pela percepção de que estas mobilizações podem contribuir com a satisfação do trabalhador, maior disposição para o trabalho, melhora no clima interno, maior fidelidade e comprometimento com a empresa e com a produtividade empresarial.

Considerando a temática pesquisada, pode-se afirmar que a gestão da qualidade de vida no trabalho das organizações vem evoluindo constantemente, visto ter sido iniciada com características predominantemente operacionais e pontuais, evoluindo na última década para ações corporativas estratégicas. O tema em questão evidencia o quanto é importante haver uma conexão entre empresa e trabalhador com práticas que possam auxiliá-los no dia a dia gerando um bem-estar para ambos. As principais considerações deste artigo convergem para a importância de um conjunto de competências em qualidade de vida no trabalho resultando em novos conhecimentos e ações, condutas empresariais, conquistas, desenvolvimento de habilidades dos empregados e da distribuição de responsabilidades entre organização e empregados. 
Esta revisão de literatura sobre qualidade de vida no trabalho certamente não se esgota aqui, deixando as portas abertas para futuras pesquisas nesta problemática.

\section{REFERÊNCIAS}

AZEVEDO, I. B.. O Prazer da Produção Científica. Piracicaba: UNIMEP, 1999.

BENTO, A. Como fazer uma revisão da literatura: Considerações teóricas e práticas. In: Revista JA (Associação Académica da Universidade da Madeira), no 65, 2012. ISSN:

Disponível:

<http://www3.uma.pt/bento/Repositorio/Revisaodaliteratura.pdf> Acesso: em 23/04/2019.

CHIAVENATO, I.. Gestão de pessoas: e o novo papel dos recursos humanos nas organizações. 2.ed. Rio de Janeiro: Elsevier, 2004.

FERNANDES, E Conte. Qualidade de Vida no Trabalho: como medir para melhorar. Salvador, BA: CASA DA QUALIDADE, 1996.

FERREIRA, A. et al. Teorias de motivação: uma análise da percepção das lideranças sobre suas preferências e possibilidade de complementaridade. In: XIII SIMPEP, Nov, 2006, Bauru.

Disponível em: <http://www.simpep.feb.unesp.br/anais/anais_13/artigos/114.pdf> Acesso em: 15 ago.2019.

GONÇALVES, A.; GUTIERREZ, G. L.; VILARTA. R. Gestão da qualidade de vida na empresa. Campinas: IPÊS Editorial, 2005.

GUEDES, S. C. Relação entre Qualidade de vida no Trabalho e Indicadores de Satisfação Profissional. 2009. 28 f. Dissertação (Mestrado em Psicologia) - Secção de Psicologia dos Recursos Humanos, do Trabalho e das Organizações, Universidade de Lisboa, Faculdade de Psicologia e de Ciências da Educação. 2009 
HERSEY, P.; BLANCHARD, K. H. Psicologia para Administradores: A Teoria e as Técnicas da Liderança Situacional. São Paulo: EPU, 1986.

LIMONGI-FRANÇA, A. C. Práticas de Recursos Humanos - PRH: conceitos, ferramentas e procedimentos. $1^{\underline{a}}$ ed. São Paulo: Atlas, 2009.

. Qualidade de Vida no Trabalho - QVT. Conceitos e práticas nas empresas da sociedade pós-industrial. $2^{\mathrm{a}}$ ed. São Paulo: Atlas, 2010.

Qualidade de Vida no Trabalho: conceitos, abordagens, inovações e desafios nas empresas brasileiras. Revista Brasileira de Medicina Psicossomática. Rio de Janeiro, v. 1. oㅡ 2. p. 79-83, abr./mai./jun. 1997.

OGATA, A.; SIMURRRO, S. Guia Prático de Qualidade de Vida: como planejar e gerenciar o melhor programa para a sua empresa. Rio de Janeiro: Alta Books, 2018.

RODRIGUES, M. V. C. Qualidade de vida no trabalho: evolução e análise no nível gerencial. 2. ed. Petrópolis, RJ: Vozes, 1994.

TOLFO, S. R. A Carreira Profissional e seus Movimentos: revendo conceitos e formas de gestão em tempos de mudanças. Revista Psicologia Organizações e Trabalho. Rev. Psicol., Organ. Trab. v.2. oㅡ 2. Florianópolis: dez. 2002.

TRALDI, M. C.; DIAS, R.. Monografia passo a passo. Edição Especial. Campinas: Editora Alínea, 2011.

Enviado: Setembro, 2019.

Aprovado: Março, 2020. 